\title{
Distribution of seisms foci during the mining of 19th eastern Iongwall and Eastern inclined longwall \#3
}

\author{
Andrii Karhapolov ${ }^{1, *}$, Svitlana Prykhodchenko ${ }^{1}$, and Vera Chelkan ${ }^{1}$ \\ ${ }^{1}$ Institute of Geotechnical Mechanics named by N. Poljakov of National Academy of Sciences of \\ Ukraine, 49005, Dnipro, Simferopolska Str., 2a, Ukraine
}

\begin{abstract}
The paper presents the results performed at the O.F. Zasiadko mine seismological observations on the registration and location of seisms that occur during the mining of the $\mathrm{m}_{3}$ bed. According to the constructed magnitude-frequency relationship for the worked out longwalls, it was concluded that the longwalls worked out in different mining-geological conditions differ in the relative energy of seisms, in their number, recording time and spatial location of foci.
\end{abstract}

\section{Introduction}

Intensive exploitation of coal deposits leads to the emergence of various dynamic manifestations of rock pressure in the rock massif. The form, nature and intensity of dynamic phenomena are extremely varied. Their development takes place not only in seismically active regions, but also in regions that are traditionally considered to be geodynamically quiet ones (regions with minor seismicity). So in Donbas after the closure of mines there is an increase in the number of technogenic earthquakes.

With an increase in the depth of the worked horizons, mining began to be complicated by the cases of large-scale manifestation of rock pressure in the form of mountain-tectonic bumps and technogenic earthquakes caused by the combined action of natural and technogenic factors. The complex nature of large dynamic phenomena in mines has arisen an increased interest in seismological methods, since seisms reflect the process of cracking, and fractured zones are potential areas of increased outburst hazard and zones of methane accumulation. The introduction of modern digital seismological monitoring systems at mining facilities has opened up wide opportunities for practical application and implementation of forecasting techniques used in seismology.

All this determines the exceptional relevance of the problem in controlling technogenic seismicity, as well as the development of effective measures to prevent the negative effects associated with large dynamic phenomena in mines. The purpose of the paper is to research the influence of mining-geological conditions on the distribution peculiarities of technogenic seismicity foci at the O.F. Zasiadko mine during the development of 19th eastern longwall and Eastern inclined longwall (EIL) \#3.

\footnotetext{
*Corresponding author: gvrvg@meta.ua
} 
Realization of this purpose required the solution of certain tasks, the main of which are: influence analysis of mining-geological conditions on the nature of the technogenic seismicity manifestation and identification of distribution peculiarities of technogenic seismicity foci in various sections of the mine.

\section{Methods}

To research the influence of mining-geological conditions on the distribution peculiarities of technogenic seismicity foci, we used the results of seismological observations conducted at the O.F. Zasiadko mine. The seismic acoustic system ARAMIS M/E, developed by the Polish company EMAG, was applied at this mine. This system is designed to record seisms, determine their energy and coordinates of the foci epicenters. The system includes massif vibration sensors (geophones) located in the mine workings, signal transmission channels and ground-based recording modules. Seismological monitoring of the rock massif was carried out when performing stoping in 18th eastern longwall, Eastern inclined longwall etc. The sensors were placed in the plane of the $m_{3}$ bed. This arrangement allowed us to cover the mine field with a total area of about $10 \mathrm{~km}^{2}$. At the sensor installation site, the $\mathrm{m}_{3}$ bed lies at a depth of $1000-1400 \mathrm{~m}$, amount of inclination is $7^{\circ}-10^{\circ}[1]$.

To analyze the distribution of technogenic seismicity foci, such indicators as the density function of seisms $P$ were calculated:

$$
P=N / S
$$

where $N$ - the number of registered seisms within the longwall; $S$-longwall square.

And the average value of the relative energy $E_{\text {av.rel }}$ :

$$
E_{\text {av.rel }}=\Sigma E_{\text {rel }} / N
$$

where $\Sigma E_{r e l}$ is the sum of energies of seisms foci within the longwall.

These indicators made it possible to compare the number and intensity of seisms that occurred in each longwall under the various mining-geological conditions.

To research the nature of technogenic fracturing, one of the methods of fractal geometry was used - the law of frequency of Guttenberg-Richter, which describes the dependence of the number of occurring phenomena on their size [2].

The law of frequency describes the destruction process of environment statistically, and the energy distribution $E$ of the number of seismic pulses $N$ recorded in the massif is written in the following formula:

$$
\lg N=A-\gamma \cdot \lg E
$$

The parameters of the magnitude-frequency relationship — inclination to the abscissa axis $\gamma$ and level $A$ - are among the most important quantitative characteristics of the seismic regime. Inclination of the graph reflects the ratio between the number of strong and quiet events, the level of the graph is their total intensity in the rock massif.

\section{Results and discussion}

The solution of the tasks was carried out using analysis of seismic data obtained at the O.F. Zasiadko mine when the seismological monitoring of 19th eastern longwall and EIL \#3.

On average, 300-400 events with relative seismic energies from $10^{1}$ to $10^{5}$ conventional units were recorded at the mine during the month. For the period 2009-2014 years, 17052 
events were recorded.

The 19th eastern longwall was mined along the strike of rocks, to the left along it there was the mined-out area of the 18th eastern longwall.

EIL \#3 was going to the rise, to the left of it there was an unmined massif complicated by tectonic disturbances, to the right a mined-out area of EIL (Fig. 1).

Seismological monitoring of the 19th eastern longwall was carried out from the beginning to the end in the mining of a longwall, while at EIL \#3, seismological observations were made for only one third of the total length of the longwall (up to the A-B line, Figure 1).

For these longwalls, an analysis of recorded seisms was performed, as well as comparison with similar results from the 18th eastern longwall and EIL was made [3].

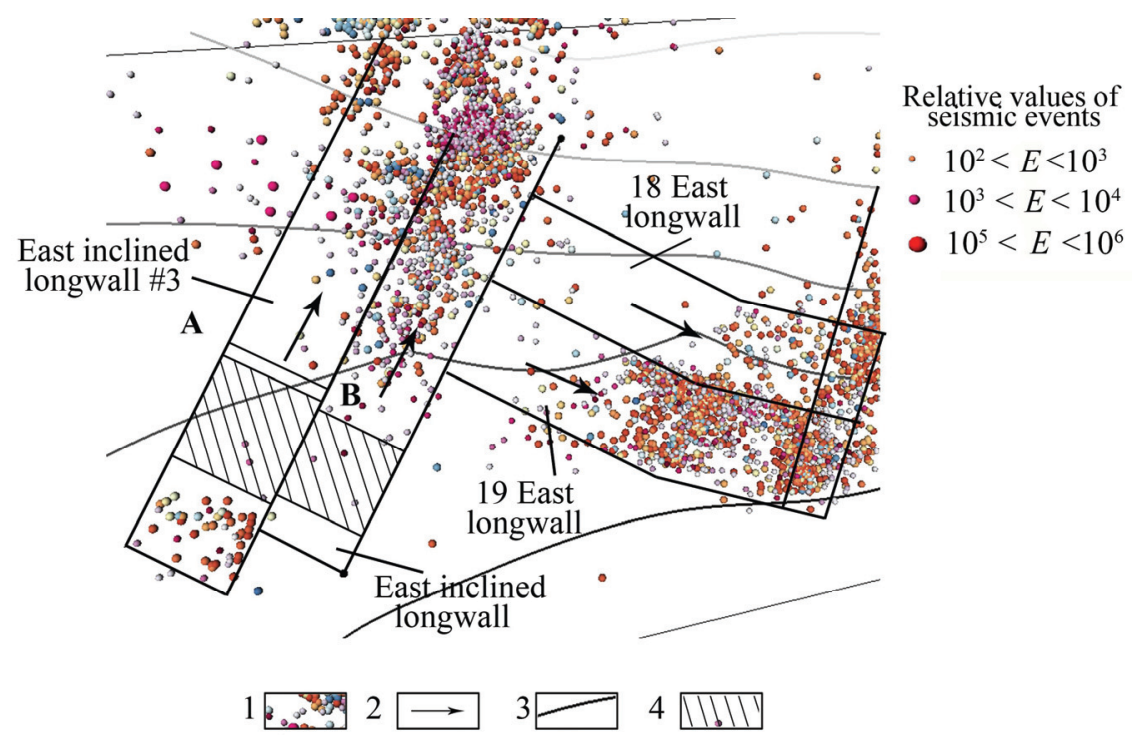

Fig. 1. Seisms of varying intensity, recordered during mining of the $m_{3}$ bed for the 2009-2014 period. 1 - projections onto the plane of seisms epicenters; 2 - the direction in the mining of a longwall; 3 isolines of the $\mathrm{m}_{3}$ bed; 4 - seismic quiescence zone.

The analysis was performed on the basis of such calculated indicators as the density function of seisms $P$, the average relative energy $E_{a v . r e l}$, as well as spatial location of foci in each longwall. The results of indicators are presented in Table 1.

Table 1. Indicators of seisms in longwalls.

\begin{tabular}{|l|c|c|c|}
\hline Longwall name & $\begin{array}{c}\text { Events } \\
\text { quantity, } \\
N \\
\text { (unit) }\end{array}$ & $\begin{array}{c}\text { Density function of } \\
\text { seisms, } P \\
\text { (unit/m } / \mathrm{m}^{2}\end{array}$ & $\begin{array}{l}\text { Average } \\
\text { relative } \\
\text { energy, } E_{a v} \\
\text { (conv. units) }\end{array}$ \\
\hline 18th eastern longwall & 1441 & 0.024 & $0.9 \cdot 10^{3}$ \\
\hline 19th eastern longwall & 3388 & 0.023 & $4.4 \cdot 10^{3}$ \\
\hline EIL & 3608 & 0.024 & $1.0 \cdot 10^{4}$ \\
\hline EIL \#3 & 372 & 0.009 & $8.1 \cdot 10^{4}$ \\
\hline
\end{tabular}

It follows from the Table that for different values of $N$ and the square of worked-out longwalls, the density of seisms has almost the same value, i.e., density function of seisms for all longwalls is alike. The low value of $P$ for EIL \#3 is probably due to the fact that monitoring was carried out for only one third of the longwall. 
The average relative energy $E_{\text {av.rel }}$ for EIL and EIL \#3 is much higher than for the 18th and the 19th eastern longwalls.

The analysis showed that, with the same density function $P$, longwalls have differences in the spatial location of the seismic foci. During the mining of the $m_{3}$ bed at the 19th eastern longwall, seisms moved after the face advance and were evenly distributed within the technological sizes of the longwall. The emergency of seisms foci were recorded mainly forward of the face and in the regular roof caving zone. This longwall is characterized by low energies of the recorded events $\left(10^{2}-10^{3}\right.$ conventional units). A similar pattern was observed when mining the 18 th eastern longwall.

A common feature in the development of the 18th and the 19th eastern longwalls is a large number of seisms with low energy of foci within the longwqall being mined. There were no significant differences in the manifestations of seismic activity of the18th and the 19th eastern longwalls.

Analysis of the distribution of technogenic seismicity foci during the mining of EIL and EIL \#3 showed the following: both longwalls are characterized by seisms with high relative energy of foci $\left(10^{4}-10^{5}\right.$ conventional units) and a small number with low $\left(10^{2}-10^{3}\right.$ conventional units).

The peculiarity of the EIL \#3 mining is that the fixed seisms foci are distributed over a considerable area, far beyond the mined-out area of the longwall (Fig. 1). This pattern of seisms distribution began to take shape during the EIL mining. The foci were located far beyond the longwall. It is possible that such a high activity of cracking $\left(10^{4}-10^{5}\right.$ conventional units) is due to the fact that the section is in a shear zone, which is currently active. The areas with the most intense cracking can be considered as zones favorable for gas accumulation, which can be associated with abnormal gas manifestations in mines [4, 5]. It is possible that the gas-dynamic event that occurred at EIL \#3 on March 24, 2015, is certainly connected with such a zone. In the longwall there was a catastrophic gas breakthrough in to the working. The gas breakthrough made an emergency, and the end result was a methane explosion.

It is characteristic that at the EIL and EIL \#3 after four months from the start of mining operations, there are periods of seismic decline in the number of recorded seisms up to their total disappearance. Seismological monitoring of the EIL showed that in October, November and December, only 17 seisms were recorded. At EIL \#3 in May, there were no single seisms, that is, a complete seismic quiescence was observed, and in June ten seisms were recorded.

The periods of decline in seismic activity coincide not only in time, but also in space. In Figure 1, the activity depletion areas for each longwall are highlighted by hatching. There is a coincidence in the location of these sections. This indicates that decline in seismic activity is due to the mining-geological conditions.

According to the available data of the registration of seisms at the mine, graphs were constructed for the 19th eastern longwall and EIL \#3 for every month of their operation.

The magnitude-frequency relationship for the 19th eastern longwall and EIL \#3 were compared with similar for the 18th eastern longwall and the EIL.

Analysis of the magnitude-frequency relationship of the 19th eastern longwall showed that they have a classic view - a straight line with a negative slope.

Figure 2 shows the magnitude-frequency relationship of the 19th eastern longwall for the period May - October. A similar behavior of the graphs was observed during the mining of the 18th eastern longwall.

The slope angles for the 18th and the 19th eastern longwalls are constantly increasing, which is evidence of an increase in the number of events with low energies. The EIL is characterized by the presence of both positive and negative slope angles of graphs, which reflects the influence of mining-geological conditions on the bed mining. 
At the EIL in October, November and December, a decline in seismic activity is observed (Fig. 3). At EIL \#3, the first four months, the magnitude-frequency relationship also looks like a straight line with a negative slope. In April, the angle value of the magnitude-frequency relationship decreases, and in May there is a complete seismic quiescence (Fig. 4).
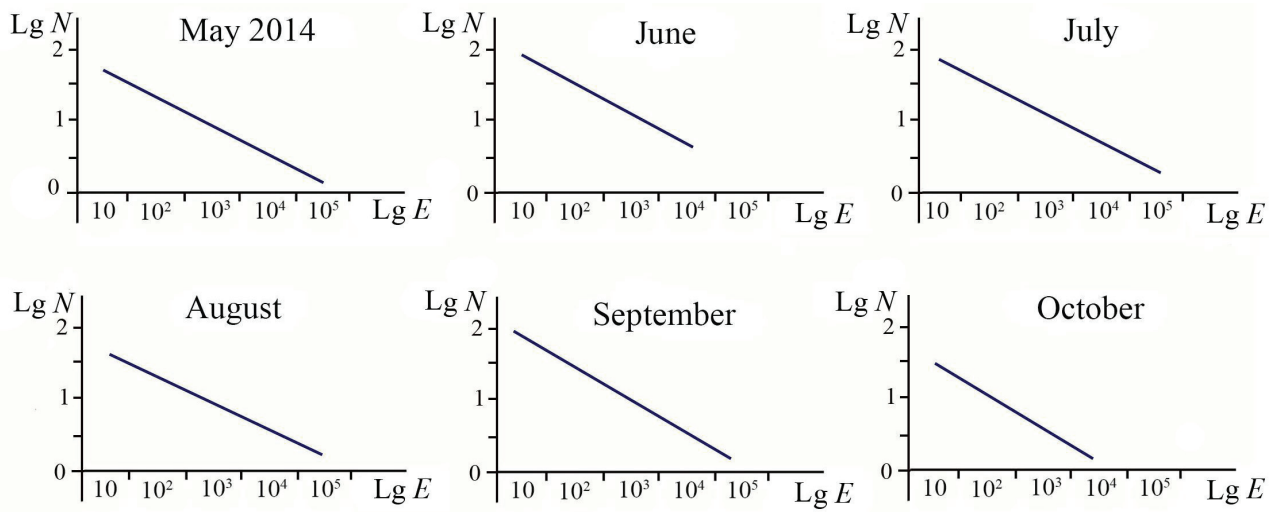

Fig. 2. Fragment of magnitude-frequency relationship of the 19th eastern longwall, May - October period, 2014.
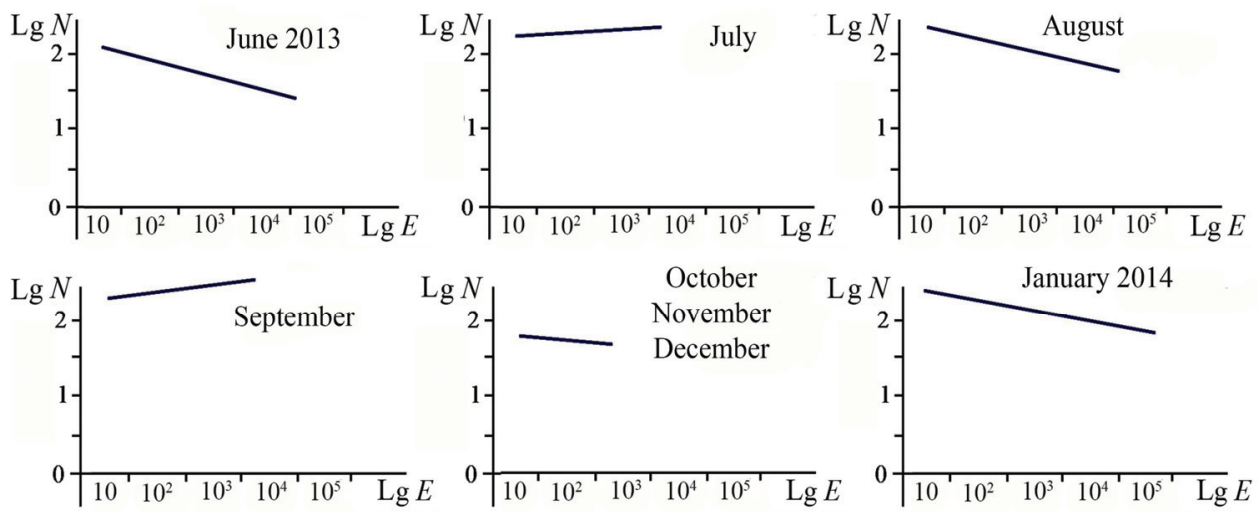

Fig 3. Fragment of magnitude-frequency relationship at the EIL, June 2013г. - January 2014.
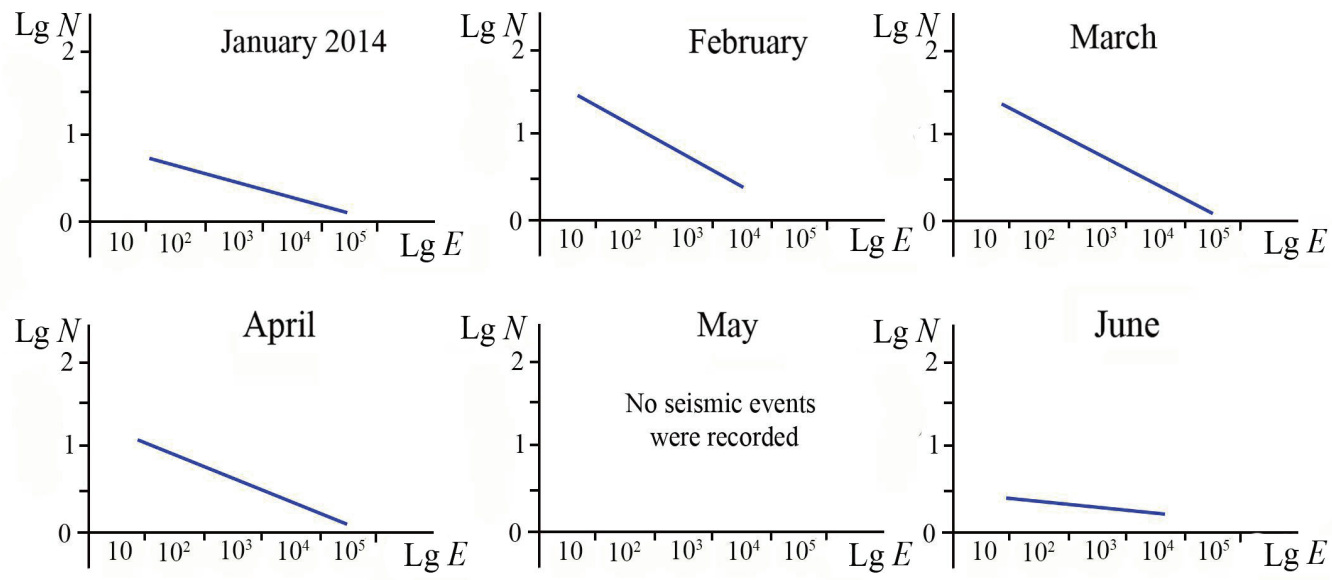

Fig 4. Fragment of magnitude-frequency relationship at EIL \#3, January - June period, 2014. 
The moments, when the value of the angles of magnitude-frequency relationship tends to zero or take negative values, coincide in time with the passage of longwalls of geological disturbances sections, bends of a bed, zones of local structures and other anomalies of the massif structure. The nature of the change in the magnitude-frequency relationship for each longwall indicates a significant difference in their seismic activity. In particular, there are fluctuations in the level of activity $A$ and slope angles $\gamma$ by months as the longwall mines. The change in the slope of magnitude-frequency relationship showed a greater dependence of the parameters on the mining-geological conditions and the degree of disturbance in the mining section and less on the time.

\section{Conclusions}

1. It is established that the distribution of the seisms foci during the mining of the 19th eastern longwall and EIL \#3 has its own characteristics, which are caused, first of all, by the influence of mining-geological conditions.

2. Longwalls located in the same mining-geological conditions - (the 18th and the 19th eastern longwalls, the EIL and EIL \#3) - have a similar view of the seisms foci distribution. A common feature at the mining of the 18th and the 19th eastern longwalls is a large number of seisms with low relative energy of foci within the mined longwall. For the EIL and EIL \#3 - a large number of seisms with high relative energy of foci, periods of seismic quiescence, the emergence of foci far beyond the boundaries of the mined longwall.

The nature of the change in the magnitude-frequency relationship for the 19th eastern longwall and EIL \#3 indicates a significant difference in their seismic activity.

Longwalls, mined out in different mining-geological conditions, differ in the relative energy of seisms, in their number, recording time and spatial location of foci.

\section{References}

1. Bulat, A.F., Makeev, S.Y., Karhapolov, A.A., Yefremov, I.A., Stavytskyi, P.H. (2010). Experimental researches of rock array state by multichannel seismic acoustic system. Geotekhnicheskaya mekhanika: Mezhvedomstvennyy sbornik nauchnykh trudov, 85, 7683

2. Tsirel, S.V., Belyaeva, L.I. (2009). Shape and slope of the magnitude-frequency relationship of dynamic events as a characteristic of the danger level and the ratio of the natural and technogenic components in the geodynamic process. Gorny informatsionnoanaliticheskiy byulleten, 11, 235-240

3. Bulat, A.F., Makeev, S.Y., Karhapolov, A.A., Zvyagilskiy, Y.L., Bokii B.V., Shkurat, E.V. (2009). The seismic acoustic system for control of rock array tense deformed state. Geotekhnicheskaya mekhanika: Mezhvedomstvennyy sbornik nauchnykh trudov, 82, 3-8

4. Lukinov, V.V., Bezruchko, K.A., Prikhodchenko, O.V., Shpak, V.U. (2012). Forecast promising areas for searching accumulations of free methane (for example mine "Butovska"). Naukovyi visnyk Natsionalnoho hirnychoho universytetu, 2, 27-35

5. Bezruchko, K., Prykhodchenko, O., Tokar, L. (2014). Prognosis for free methane traps of structural and tectonic type in Donbas. Progressive Technologies of Coal, Coalbad Methane, Ores Mining. London: Taylor \& Francis Group. 267-271 